\title{
Physicians' knowledge and practices regarding screening adult patients for adverse childhood experiences: a survey
}

\author{
Robert G. Maunder ${ }^{1 *}$, Jonathan J. Hunter ${ }^{1}$, David W. Tannenbaum², Thao Lan Le ${ }^{1}$ and Christine Lay ${ }^{3}$
}

\begin{abstract}
Background: Adverse Childhood Experiences (ACEs) are common and associated with many illnesses. Most physicians do not routinely screen for ACEs. We aimed to determine if screening is related to knowledge or medical specialty, and to assess perceived barriers.
\end{abstract}

Methods: Physicians in Ontario, Canada completed an online survey in 2018-2019. Data were analyzed in 2019.

Results: Participants were 89 family physicians, 46 psychiatrists and 48 other specialists. Participants screened for ACEs "never or not usually" $(N=58,31.7 \%)$, "when indicated" ( $N=67,36.6 \%)$, "routinely" $(N=50,27.3 \%)$ or "other" $(N=5$, 2.7\%). Screening was strongly associated with specialty $\left(\mathrm{Chi}^{2}=181.0, p<.001\right)$. The modal responses were: family physicians - "when indicated" (66.3\%), psychiatrists - "routinely" (91.3\%), and other specialists - "never or not usually" (77.1\%). Screening was not related to knowledge of prevalence of ACEs, or of the link between ACEs and mental health, but was significantly associated with knowing that ACEs are associated with physical health. Knowing that ACEs are linked to stroke, ischemic heart disease, COPD, and diabetes predicted greater screening (Chi ${ }^{2}$ 15.0-17.7, each $p \leq .001)$. The most prevalent perceived barriers to screening were lack of mental health resources $(59.0 \%)$, lack of time (59.0\%), concern about causing distress (49.7\%) and lack of confidence (43.7\%).

Conclusions: Enhancing knowledge about ACEs' negative influence on physical illness may increase screening. Efforts to promote screening should address concerns that screening is time-consuming and will increase referrals to mental health resources. Education should focus on increasing confidence with screening and with managing patient distress.

Keywords: Childhood adversity, Child abuse, Medical history taking, Prevention

\section{Background}

Knowledge of the prevalence of childhood adversity and its lifelong effects on health has been advanced by the concept of Adverse Childhood Experiences (ACEs), which are typically defined to include ten types of exposure: physical, sexual, or emotional abuse, emotional or material neglect, witnessing domestic violence, permanent parental separation, or growing up with a household

\footnotetext{
* Correspondence: Robert.maunder@sinaihealthsystem.ca

'Department of Psychiatry, Sinai Health System and University of Toronto, Room 915, Mount Sinai Hospital, 600 University Ave, Toronto, ON M5G 1X5, Canada

Full list of author information is available at the end of the article
}

member with mental illness, addiction or incarceration [1]. Most adults (50-60\%) report at least 1 ACE [1-3]. The more ACEs a child is exposed to, the higher the risk of many health problems, including cardiovascular disease [3-5], chronic obstructive pulmonary disease [6, 7], liver disease $[8,9]$, cancer $[8,10-14]$, infertility [15], mental illnesses and addiction [3, 16, 17]. ACEs also contribute to burden in healthcare through their association to unexplained symptoms [18], "difficult" providerpatient interactions [19], and high health care utilization [20-22]. As a result, identifying that an adult patient has

C C The Author(s). 2020 Open Access This article is licensed under a Creative Commons Attribution 4.0 International License, which permits use, sharing, adaptation, distribution and reproduction in any medium or format, as long as you give appropriate credit to the original author(s) and the source, provide a link to the Creative Commons licence, and indicate if changes were made. The images or other third party material in this article are included in the article's Creative Commons licence, unless indicated otherwise in a credit line to the material. If material is not included in the article's Creative Commons licence and your intended use is not permitted by statutory regulation or exceeds the permitted use, you will need to obtain permission directly from the copyright holder. To view a copy of this licence, visit http://creativecommons.org/licenses/by/4.0/. The Creative Commons Public Domain Dedication waiver (http://creativecommons.org/publicdomain/zero/1.0/) applies to the data made available in this article, unless otherwise stated in a credit line to the data. 
experienced childhood adversity may contribute to secondary prevention of many adverse health outcomes.

In spite of their relevance to health, ACEs are not usually discussed in adult health care interactions. Both patients and doctors report that $<10 \%$ of patients are asked about ACEs [23, 24]. Patients indicate that they understand the relevance of ACEs and most do not object to being asked $[23,25]$. Indeed, among patients who have experienced sexual abuse, most would like to be asked about their experience if it is done sensitively and supportively [26, 27]. Thus, barriers to discussing ACEs are mostly on the healthcare provider's side of the interaction.

As a step towards designing interventions to encourage physicians to ask about childhood adversity (hereafter "screening ACEs"), we aimed to determine if physicians' typical screening practice is related to knowledge about ACEs and to medical specialty. We also wished to identify the most common barriers to screening.

\section{Methods}

We conducted an anonymous, online survey that was open to practicing physicians in Ontario, Canada. In order to reach representative Ontario physicians, we asked organizations who represent physicians of all specialties, in all geographic regions of Ontario to distribute information about the survey. These included Ontario's five medical schools, located in Toronto, London, Hamilton, Kingston, Ottawa and Northern Ontario, and the Ontario College of Family Physicians. The University of Toronto Faculty of Medicine did not distribute the information to all faculty, but it was distributed by four of its largest departments (Family and Community Medicine, Medicine, Obstetrics and Gynecology, and Psychiatry). These organizations notified members actively (e.g. an email message from a department head), passively (e.g. a notice in a newsletter) or not at all. Two prizes of $\$ 200$ were offered to random participants.

Survey questions were developed by one author (RGM) and iteratively edited by other members of the research team. We surveyed participants' age, gender, specialty, and years in practice. To determine usual practice regarding screening ACEs we asked "How often do you ask adult patients if they experienced abuse, neglect or other serious adversity when they were children?" with five possible responses ("Routinely. I have asked almost all of my patients this at least once," "When it is indicated. I ask patients about childhood adversity when I think it is an issue," "Not usually. It would be exceptional for me to discuss this with a patient," "Never," "Other").

Knowledge was tested by estimating the prevalence of childhood physical and sexual abuse in boys and in girls and the prevalence of all ACES (after providing a definition) on a sliding scale from 0 to $100 \%$, and selecting which health problems from a list are associated with ACEs (ischemic heart disease, stroke, diabetes, chronic obstructive lung disease, hepatitis C, major depression, substance use disorder, generalized anxiety disorder, smoking, obesity; all have evidence of association). Participants were asked to endorse seven perceived barriers to screening from a list derived by a review of literature, by barriers voiced by colleagues at educational presentations, and by the clinical experience of the research team. The items were: not believing the information would alter care; concern that it will cause distress to patients; not feeling confident about how to ask; not having mental health resources to refer patients to if they reveal problems; concern that patients will find the question irrelevant; not having enough time; feeling embarrassed or uncomfortable; other.

Descriptive statistics were used to describe the characteristics of participants. Proportions were calculated as percentage and 95\% confidence interval (CI). Relationships between variables were tested with $\mathrm{Chi}^{2}$ tests and analysis of variance (ANOVA) as appropriate.

\section{Results}

Of 184 participants, there were 89 family physicians, 46 psychiatrists and 48 other specialists; 103 (56.3\%) were female. The mean time practicing was 18.9 (standard deviation 13.3) years. The response rate could not be calculated because the number of physicians informed of the study is unknown.

Estimates of the prevalence of physical and sexual abuse and of ACEs in general are shown in Table 1. Most participants knew that ACEs are associated with Major Depression (85.8, 95\%CI 79.9-90.5), Generalized Anxiety Disorder (86.9, 95\%CI 81.1-91.4) and Substance Use Disorder (85.2, 95\%CI 79.3-90.0). Fewer knew that ACEs are associated with smoking $(74.9,95 \% \mathrm{CI} 67.9-$ $81.0)$ and obesity (72.1, 95\%CI 65.9-78.5). This knowledge did not differ by specialty. Knowledge of the association of ACEs to physical illnesses was less common and for each physical illness tested except Hepatitis C differed by specialty, with psychiatrists recognizing the link more commonly (Fig. 1).

With regard to usual practice, 58 physicians (31.7\%) screen for ACEs "never" or "not usually," 67 (36.6\%) screen "when indicated," 50 (27.3\%) screen "routinely," and 5 (2.7\%) selected "other." Screening practice was strongly associated with specialty $\left(\mathrm{Chi}^{2}=181, p<.001\right)$; the modal response for family physicians was screening "when indicated" (66.3\%), for psychiatrists "routinely" (91.3\%), and for other specialists "never or not usually" (77.1\%).

Screening practice was not related to knowledge of the prevalence of ACEs, nor of the link between ACEs and mental health or health behavior (data not shown). 
Table 1 Physicians' estimates of the prevalence of childhood abuse and of ACEs

\begin{tabular}{|c|c|c|c|c|c|c|c|c|}
\hline & \multicolumn{2}{|c|}{$\begin{array}{l}\text { Family Physicians } \\
N=89\end{array}$} & \multicolumn{2}{|l|}{$\begin{array}{l}\text { Psychiatrists } \\
N=46\end{array}$} & \multicolumn{2}{|c|}{$\begin{array}{l}\text { Other Specialists } \\
N=48\end{array}$} & \multicolumn{2}{|c|}{ ANOVA } \\
\hline & $M \pm S D$ & $95 \% \mathrm{Cl}$ & $M \pm S D$ & $95 \% \mathrm{Cl}$ & $M \pm S D$ & $95 \% \mathrm{Cl}$ & $\bar{F}$ & $p$ \\
\hline \multicolumn{9}{|c|}{ Sexual Abuse } \\
\hline Girls & $26.4 \pm 13.5$ & $23.6-29.2$ & $32.0 \pm 17.7$ & $26.7-37.3$ & $23.9 \pm 12.6$ & $20.2-27.6$ & 3.7 & .03 \\
\hline Boys & $17.9 \pm 13.4$ & $15.1-20.7$ & $21.2 \pm 14.5$ & $16.9-25.5$ & $14.5 \pm 8.0$ & $12.2-16.8$ & 3.2 & .04 \\
\hline \multicolumn{9}{|c|}{ Physical Abuse } \\
\hline Girls & $29.9 \pm 13.6$ & $27.0-32.8$ & $32.6 \pm 16.3$ & $27.8-37.4$ & $30.4 \pm 12.6$ & $26.8-34.0$ & 0.5 & .61 \\
\hline Boys & $30.9 \pm 13.9$ & $28.0-33.8$ & $36.8 \pm 16.8$ & $31.8-41.8$ & $29.0 \pm 16.8$ & $24.1-33.9$ & 3.2 & .04 \\
\hline Any ACEs & $45.7 \pm 16.5$ & $42.2-49.2$ & $49.7 \pm 16.0$ & $45.0-54.4$ & $47.2 \pm 17.8$ & $42.0-52.4$ & 0.8 & .44 \\
\hline
\end{tabular}

M mean, SD standard deviation, 95\% Cl 95\% confidence interval, ANOVA Difference between groups assessed by Analysis of Variance

However, there was a significant positive relationship between knowledge that ACEs are associated with physical diseases and frequency of screening ACEs (Fig. 2).

The most prevalent perceived barriers to screening ACEs were not having mental health resources to refer patients to if they reveal problems (59.0\%), not having enough time (59.0\%), concern that it will cause distress to patients (49.7\%) and not feeling confident about how to ask (43.7\%). Less frequently endorsed barriers were not believing the information would alter care $(41.0 \%)$, concern that patients will find the question irrelevant (30.1\%), and feeling embarrassed or uncomfortable (28.4\%).

\section{Discussion}

Physicians' screening of ACEs was related to both specialty and knowledge of ACEs' physical health impact. Screening ACEs was routine for most psychiatrists, less frequent among family physicians, and typically not done by other specialists.
Knowledge that ACEs are associated with mental illness and addiction was widespread and unrelated to usual ACE screening practice. Knowledge that ACEs are associated with physical illness was less common and was significantly associated with screening practice. Thus, knowing ACEs increase the risk of physical illness is a potential target of education to encourage ACE screening. However, this knowledge was conflated with medical specialty. It is not known if it is knowledge or the nature of different specialty training and practices that influences screening.

Estimates of the prevalence of physical and sexual abuse differed significantly by specialty, with higher estimates reported by psychiatrists. With respect to accuracy, compared to the 2012 Canadian Community Health Survey, most physician estimates of abuse were overestimates [3]. Physician estimates of ACEs of all types were close to what has been reported in populationbased samples [2]. Thus, low rates of routine screening

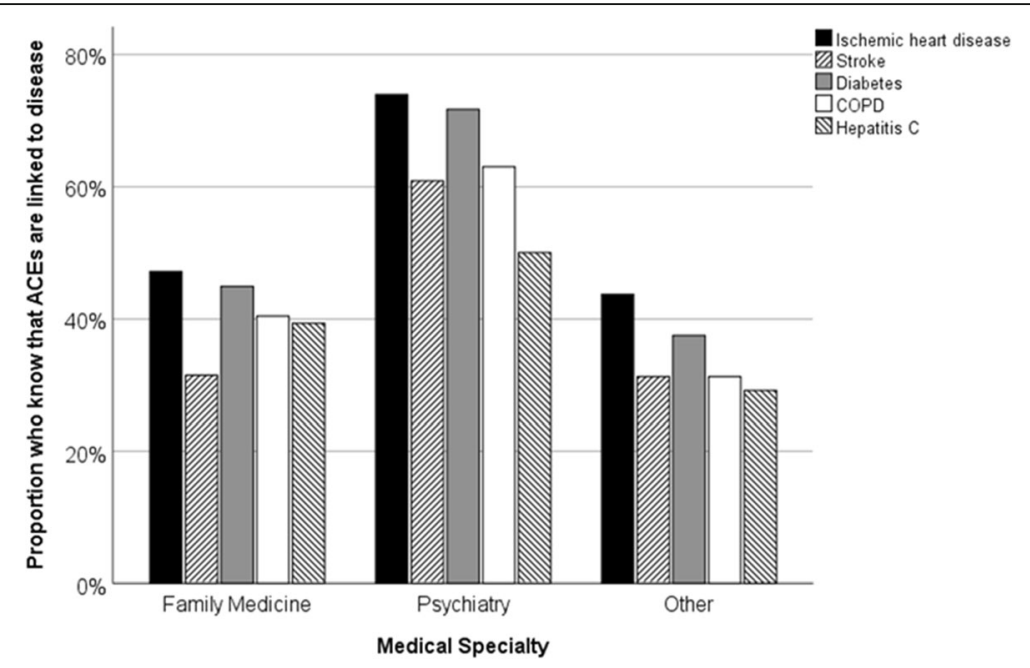

Fig. 1 Relationship between medical specialty and knowledge that selected physical diseases are associated with ACEs. Ischemic Heart Disease: $\mathrm{Chi}^{2}=10.9, p=.004$; Stroke: $\mathrm{Chi}^{2}=12.6, p=.002$; Diabetes: $\mathrm{Chi}^{2}=12.6, p=.002$; Chronic Obstructive Pulmonary Disease: Chi $^{2}=10.4, p=.006$; Hepatitis C: $\mathrm{Chi}^{2}=4.3, p=.12$ 


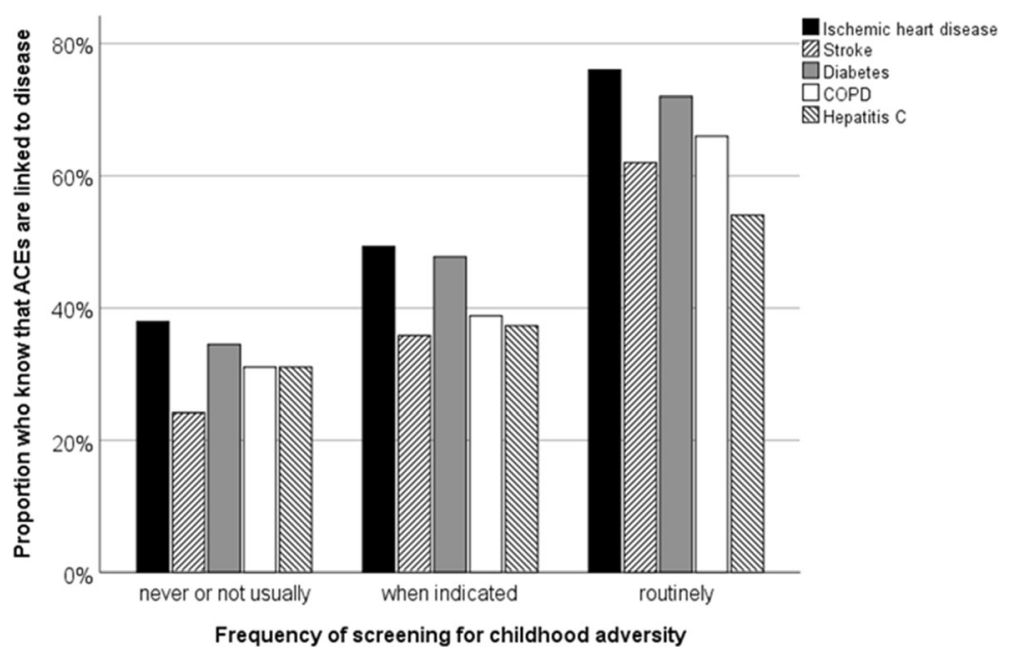

Fig. 2 Relationship between usual screening behavior and knowledge that selected physical diseases are associated with ACEs. Five participants who indicated that their usual practice is "other" not shown. Ischemic Heart Disease: Chi $^{2}=17.7, p<.001$; Stroke: Chi $^{2}=16.7, p<.001$; Diabetes: $\mathrm{Chi}^{2}=15.6, p<.001$; Chronic Obstructive Pulmonary Disease: $\mathrm{Chi}^{2}=15.0, p<.001$; Hepatitis C: Chi $^{2}=6.2, p=.10$

do not appear to be due to underestimating the prevalence of childhood adversity.

The most frequently endorsed perceived barriers were consistent with those that have been reported previously $[28,29]$. This suggests another potential target for education, since available evidence suggests that screening ACEs requires less than $5 \mathrm{~min}$ and does not necessarily lead to new needs for mental health resources [30].

This study is limited by the method of survey distribution which precludes calculating a response rate, by selfselection of participants, which may introduce biases, and by the relatively small sample size. The study design does not allow confidence that the respondents were characteristic of all practicing physicians.

The intent of the study is built on the assumption that screening will facilitate secondary prevention and improve patient care. Discussion of ACEs in a safe and accepting circumstance may improve physician-patient alliance, as is supported by qualitative evidence from patients who have experienced adversity [26]. Asking about ACEs also supports trauma-informed care [27], for example, providing information that may reduce inadvertent re-traumatization during medical procedures. However, the assumption that screening adult patients for ACEs improves patient outcomes has not yet been directly tested.

\section{Conclusions}

Low rates of routine screening do not appear to be due to underestimating the prevalence of childhood adversity. However, knowledge that ACEs are associated with physical illness was significantly associated with screening practice and is a potential target of education to encourage ACE screening. Common barriers to screening include the perception that it will be time consuming and will result in the need for referral for mental health interventions.

\section{Abbreviations}

ACEs: Adverse childhood experiences; ANOVA: Analysis of variance; Cl: Confidence interval; COPD: Chronic obstructive pulmonary disease; M: Mean; SD: Standard deviation

\section{Acknowledgements}

Not Applicable.

All authors approved the submitted version and are personally accountable for their own contributions and to ensure that questions related to the accuracy or integrity of any part of the work, even ones in which the author was not personally involved, are appropriately investigated, resolved, and the resolution documented in the literature.

\section{Authors' contributions}

RGM made substantial contributions to the conception and design of the survey, acquisition and analysis of data, interpretation of data and drafting of the report. JJH and DWT made substantial contributions to the conception and design of the survey, acquisition and interpretation of data. TLL and CL made substantial contributions to the conception of the survey and interpretation of data. The authors read and approved the final manuscript.

\section{Funding}

This work was supported by the Chair in Health and Behaviour at Sinai Health System, funded by Sinai Health System and the University of Toronto, and by the Medical Psychiatry Alliance. The funding body had no role in study design, data collection, analysis, interpretation of data, nor in writing the manuscript.

\section{Availability of data and materials}

The datasets used and analysed during the current study are available from the corresponding author on reasonable request.

\section{Ethics approval and consent to participate}

This research involved human subjects and was performed in accordance with the Declaration of Helsinki and approved by the Mount Sinai Hospital Research Ethics Board (Ref: 18-0140-E). All survey participants provided written informed consent. 


\section{Consent for publication}

Not Applicable.

\section{Competing interests}

The authors declare that they have no competing interests.

\section{Author details}

'Department of Psychiatry, Sinai Health System and University of Toronto, Room 915, Mount Sinai Hospital, 600 University Ave, Toronto, ON M5G 1X5, Canada. ${ }^{2}$ Department of Family Medicine, Sinai Health System and University of Toronto, Toronto, Canada. ${ }^{3}$ Department of Medicine, Women's College Hospital and University of Toronto, Toronto, Canada.

Received: 5 July 2019 Accepted: 18 March 2020

Published online: 15 April 2020

\section{References}

1. Felitti VJ, Anda RF, Nordenberg D, Williamson DF, Spitz AM, Edwards V, et al. Relationship of childhood abuse and household dysfunction to many of the leading causes of deaths in adults: the adverse childhood experiences (ACE) study. Am J Prev Med. 1998;14:245-58.

2. Gilbert LK, Breiding MJ, Merrick MT, Thompson WW, Ford DC, Dhingra SS, et al. Childhood adversity and adult chronic disease: an update from ten states and the District of Columbia, 2010. Am J Prev Med. 2015:48(3):345-9.

3. Afifi TO, MacMillan HL, Boyle M, Taillieu T, Cheung K, Sareen J. Child abuse and mental disorders in Canada. CMAJ. 2014;186(9):E324-32.

4. Anda RF, Brown DW, Felitti VJ, Bremner JD, Dube SR, Giles WH. Adverse childhood experiences and prescribed psychotropic medications in adults. Am J Prev Med. 2007:32(5):389-94.

5. Suglia SF, Koenen KC, Boynton-Jarrett R, Chan PS, Clark CJ, Danese A, et al. Childhood and adolescent adversity and Cardiometabolic outcomes: a scientific statement from the American Heart Association. Circulation. 2018; 137(5):e15-28

6. Afifi TO, MacMillan HL, Boyle M, Cheung K, Taillieu T, Turner S, et al. Child abuse and physical health in adulthood. Health Rep. 2016;27(3):10-8.

7. Shields ME, Hovdestad WE, Gilbert CP, Tonmyr LE. Childhood maltreatment as a risk factor for COPD: findings from a population-based survey of Canadian adults. Int J Chron Obstruct Pulmon Dis. 2016;11:2641-50.

8. Bellis MA, Hughes K, Leckenby N, Hardcastle KA, Perkins C, Lowey H. Measuring mortality and the burden of adult disease associated with adverse childhood experiences in England: a national survey. J Public Health (Oxf). 2015;37(3):445-54.

9. Dong M, Dube SR, Felitti VJ, Giles WH, Anda RF. Adverse childhood experiences and self-reported liver disease: new insights into the causal pathway. Arch Intern Med. 2003;163(16):1949-56.

10. Brown DW, Anda RF, Felitti VJ, Edwards VJ, Malarcher AM, Croft JB, et al. Adverse childhood experiences are associated with the risk of lung cancer: a prospective cohort study. BMC Public Health. 2010;10:20.

11. Fuller-Thomson E, Brennenstuhl S. Making a link between childhood physical abuse and cancer: results from a regional representative survey. Cancer. 2009;115(14):3341-50.

12. Kelly-Irving M, Lepage B, Dedieu D, Lacey R, Cable N, Bartley M, et al. Childhood adversity as a risk for cancer: findings from the 1958 British birth cohort study. BMC Public Health. 2013;13:767.

13. Brown MJ, Thacker $L R$, Cohen SA. Association between adverse childhood experiences and diagnosis of cancer. PLoS One. 2013;8(6):e65524.

14. Hughes K, Bellis MA, Hardcastle KA, Sethi D, Butchart A, Mikton C, et al. The effect of multiple adverse childhood experiences on health: a systematic review and meta-analysis. Lancet Public Health. 2017:2(8):e356-e66.

15. Jacobs MB, Boynton-Jarrett RD, Harville EW. Adverse childhood event experiences, fertility difficulties and menstrual cycle characteristics. J Psychosom Obstet Gynaecol. 2015;36(2):46-57.

16. Chartier MJ, Walker JR, Naimark B. Childhood abuse, adult health, and health care utilization: results from a representative community sample. Am J Epidemiol. 2007;165(9):1031-8.

17. Afifi TO, Enns MW, Cox BJ, Asmundson GJ, Stein MB, Sareen J. Population attributable fractions of psychiatric disorders and suicide ideation and attempts associated with adverse childhood experiences. Am J Public Health. 2008;98(5):946-52.

18. Maunder RG, Hunter JJ, Atkinson L, Steiner M, Wazana A, Fleming AS, et al. An attachment-based model of the relationship between childhood adversity and somatization in children and adults. Psychosom Med. 2017; 79(5):506-13.

19. Porcerelli JH, Jones JR, Klamo R, Heeney R. Childhood abuse in adults in primary care: empirical findings and clinical implications. Int J Psychiatry Med. 2017;52(3):265-76.

20. Chartier MJ, Walker JR, Naimark B. Separate and cumulative effects of adverse childhood experiences in predicting adult health and health care utilization. Child Abuse Negl. 2010;34(6):454-64.

21. Kamiya $Y$, Timonen $V$, Kenny RA. The impact of childhood sexual abuse on the mental and physical health, and healthcare utilization of older adults. Int Psychogeriatr. 2016;28(3):415-22.

22. Fang X, Brown DS, Florence CS, Mercy JA. The economic burden of child maltreatment in the United States and implications for prevention. Child Abuse Negl. 2012;36(2):156-65.

23. Tink W, Tink JC, Turin TC, Kelly M. Adverse childhood experiences: survey of resident practice, knowledge, and attitude. Fam Med. 2017:49(1):7-13.

24. Friedman LS, Samet JH, Roberts MS, Hudlin M, Hans P. Inquiry about victimization experiences. A survey of patient preferences and physician practices. Arch Intern Med. 1992;152(6):1186-90.

25. Gillespie RJ, Folger AT. Feasibility of assessing parental ACEs in pediatric primary care: implications for practice-based implementation. J Child Adolesc Trauma. 2017:10(3):249-56.

26. Berry KM, Rutledge CM. Factors that influence women to disclose sexual assault history to health care providers. J Obstet Gynecol Neonatal Nurs. 2016;45(4):553-64

27. Schachter CL, Radomsky NA, Stalker CA, Teram E. Women survivors of child sexual abuse. How can health professionals promote healing? Can Fam Physician. 2004;50:405-12.

28. Weinreb L, Savageau JA, Candib LM, Reed GW, Fletcher KE, Hargraves JL. Screening for childhood trauma in adult primary care patients: a crosssectional survey. Prim Care Companion J Clin Psychiatry. 2010;12(6). https:// doi.org/10.4088/PCC.10m00950blu.

29. Esden JL. Adverse childhood experiences and implementing traumainformed primary care. Nurs Pract. 2018;43(12):10-21.

30. Glowa PT, Olson AL, Johnson DJ. Screening for adverse childhood experiences in a family medicine setting: a feasibility study. J Am Board Fam Med. 2016;29(3):303-7.

\section{Publisher's Note}

Springer Nature remains neutral with regard to jurisdictional claims in published maps and institutional affiliations.

\section{Ready to submit your research? Choose BMC and benefit from}

- fast, convenient online submission

- thorough peer review by experienced researchers in your field

- rapid publication on acceptance

- support for research data, including large and complex data types

- gold Open Access which fosters wider collaboration and increased citations

- maximum visibility for your research: over $100 \mathrm{M}$ website views per year

At BMC, research is always in progress.

Learn more biomedcentral.com/submission 